regarding material-transfer agreements, although when contacted by Nature he said he was unaware of Green's claimed difficulties. Sands says that he subsequently contacted Goldstein to try to "clear up any misunderstanding", but at the time of going to press Goldstein said he had not received the material.

Sands says that, since the publication of the paper, his company has transferred materials to 41 non-commercial investigators at 27 institutions. He declined to provide a list of the investigators, but named half a dozen researchers at four universities. Interviews with some of these showed a substantial fee was paid for unpublished material, while one institution was asked to cede reach-through rights to Lexicon.

These concerns prompted HHMI officials to circulate a memorandum to its 300 researchers. HHMI spokesman Robert Potter issued a statement: "Several HHMI investigators have expressed interest in

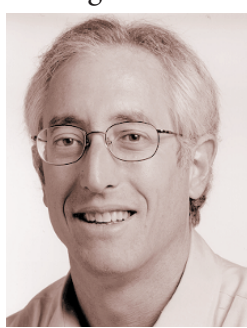
having access to Omnibank and related resources owned by Lexicon for their research. So far, we have been unable to come to terms on an arrangement for such Goldstein: faced with access."

“onerous" terms.

To researchers, the conflict shows that enforcement is needed to make material from the published domain more readily available. Such problems remain, says Green, because "no one wants to take responsibility for the enforcement".

Green argues that the National Institutes of Health, which last spring issued suggested guidelines for making materials available from its own funded research (see Nature 399, 291; 1999), should take a greater responsibility for the situation. NIH director Harold Varmus, a champion of ready access to published research materials, was unavailable for comment.

Several scientists said major journals that have policies on access to materials from published research should prohibit authors from publishing if they break the rules on material transfers. Rex Dalton

Nature's policy is that materials should be made freely available. This is made explicitly clear to all authors as a condition of publication. Where the conditions are subsequently broken, Nature reserves the right, as one possible sanction, to refuse to consider further papers from the authors or even, where necessary, the institution or company concerned. We are contacting the authors at Lexicon and will inform readers of the outcome. The editor

\title{
Company to use advertising to cover Pubmed Central costs
}

\section{Baltimore}

A private company that provides researchers with information about funding opportunities and other activities announced last week that it will provide 'front end' services on Pubmed Central, the free repository for research results which the National Institutes of Health (NIH) plans to launch in January.

These services will enable societies and individuals to publish peer-reviewed research and are to be provided by Community of Science (COS), based in Baltimore, which keeps profiles of 500,000 researchers globally.

Huntington Williams, COS's president said his company was trying to formulate an economic model for publishing on Pubmed Central. The costs of processing and reviewing manuscripts would be covered by online advertising and direct marketing aimed at the scientists who select the reviewers and the reviewers themselves.

COS is the first organization to propose a business model that would allow electronic journals which publish on Pubmed Central - and therefore have no subscription revenue - to cover the costs of arranging for the review of scientific papers, and editing the text and illustrations into a standard format ready for publication.

These costs would be covered by selling web advertising and web marketing targeted at the reviewers themselves and at the boards of researchers that select them. The existing COS database would enable such advertising and marketing to be tightly targeted at these scientists' interests and personal habits.

Williams refused to speculate over how much money could be raised in this way, but

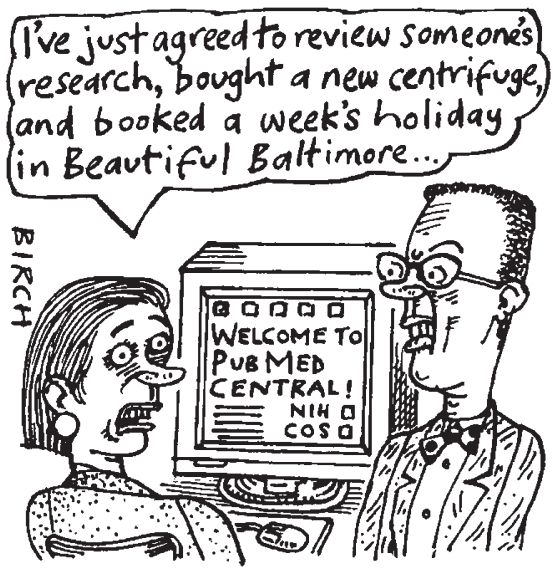

the newsletter Science and Government Report quotes COS officials as saying that, while unspecified journals spend $\$ 4000$ to process each paper, the new system might do it for $\$ 250$. The model assumes that this amount, plus profit, could be generated by advertising and marketing aimed at referees.

Williams said the model would enable COS subscribers, as well as societies who wanted to publish their journals on Pubmed Central, to publish results in the new repository. COS and the societies would revenues from the advertising and marketing, he said.

David Lipman, director of the National Center for Biotechnology Information at the $\mathrm{NIH}$ and one of the architects of Pubmed Central, said that COS's plans were one of "a wide variety of business models" which the repository would accommodate. $\mathrm{He}$ adds that plans for PubMed Central's launch are focusing mainly on the part incorporating peer-reviewed content.

Colin Macilwain

\section{Optical society vote sees off merger}

San Diego

Members of the Optical Society of America (OSA) voted last week not to merge with the International Society for Optical Engineering (SPIE), ending months of contentious campaigning at the two societies.

The result was announced last week at the society's annual meeting in Santa Clara, California. SPIE had voted by mail earlier in the summer, with the result to be announced on Tuesday of this week. But the response from the OSA membership kills the merger, which was first mooted in early 1998.

OSA's leadership had sought the merger to create a more powerful organization. But criticism of the merger proposal grew as vocal dissidents expressed concerns that the research-orientated OSA might be threatened by SPIE and its focus on applied research (see Nature 398, 547; 1999).

The OSA voted against the merger by 51 per cent (2,551 votes) to 49 per cent $(2,420$ votes). A two-thirds majority of voting members was needed to approve the merger.

"The members have spoken," said Anthony E. Siegman, OSA's president and a leading proponent of the merger. "In their view, a merger of OSA and SPIE is not in the best interests of the society at this time."

Daniel V. F. James, a theoretical physicist at Los Alamos National Laboratory in New Mexico and a critic of the merger proposal, said of the vote: "We are happy; it was the correct decision." 